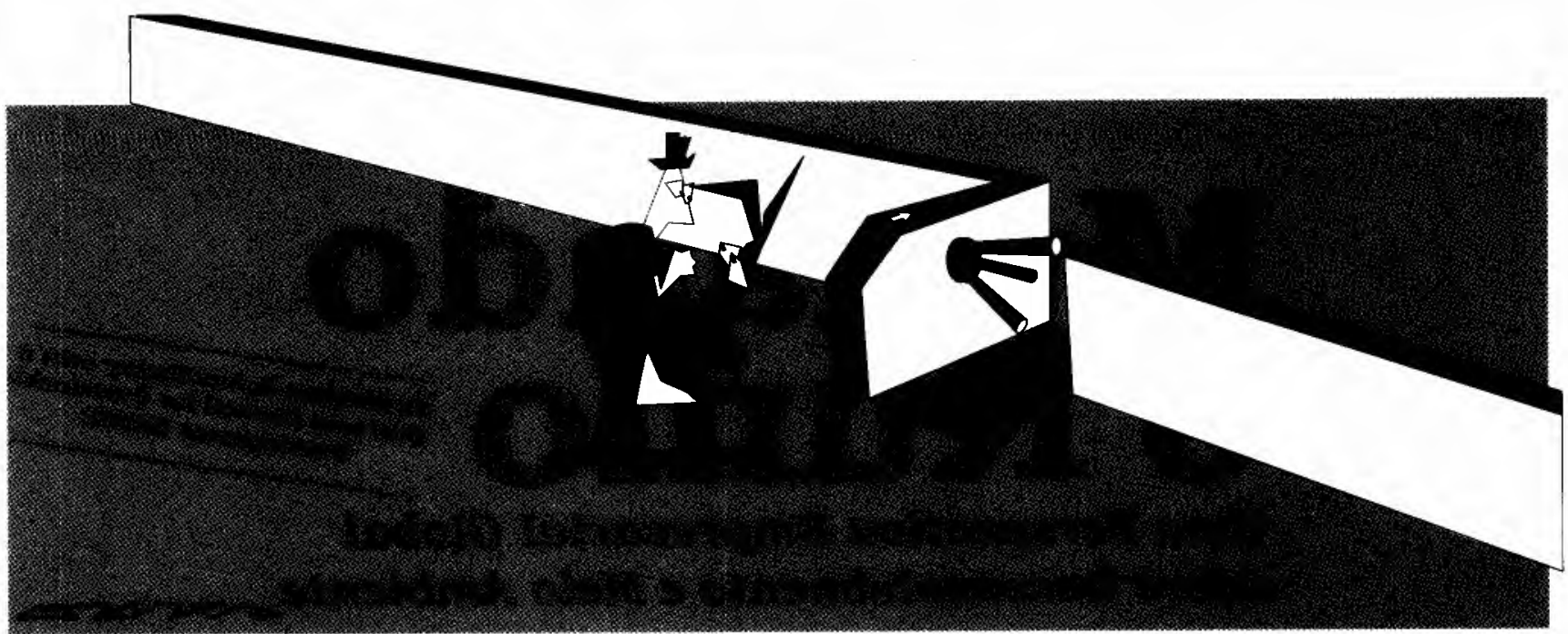

\title{
TEORIA DA ORGANIZAÇÃO E SOCIEDADES SUBDESENVOLVIDAS
}

"Uma estrutura social, racionalmente organizada, envolve padrões de atividade claramente definidos, nos quais, segundo a maneira ideal, cada série ou conjunto de açóes está funcionalmente relacionado com os propósitos da organização."

Robert K. Merton

\section{Carlos Osmar Bertero}

Professor Titular e Chefe do Departamento de Administração Geral e Recursos Humanos da EAESP/FGV.

* RESUMO: O texto aborda a questão da Teoria Organizacional como existente nos meados da década de 1960, enquanto expressão na racionalidade instrumental weberiana. Fazendo uso de um referencial teórico estruturalista, como o apresentado por Amitai Etzioni, procura dimensionar a lacuna entre as sociedades ocidentais $e$ as não ocidentais. O centro do argumento é que as sociedades ocidentais, ao longo de seu processo formativo, acabaram por caracterizar-se como mais adequadas ao surgimento e funcionamento das organizações formais enquanto expressão da racionalidade instrumental. Exigências organizacionais formais seriam a subordinação do interesse individual ao geral, adesão a uma postura epistemológica pragmática, comportamento calcado em neutralidade emocional (Sine ira ac studio) $e$ capacidade de objetivação sob a forma de ação organizada. As sociedades não ocidentais apresentariam, por sua própria formação e gênese, dificuldades maiores para abrigar e desenvolver organizações formais, caindo no círculo vicioso da baixa densidade organizacional.

PALAVRAS-CHAVE: Organização formal, racionalidade instrumental, análise funcional e estruturalista, sociedades não ocidentais.

* ABSTRACT: The article approaches organizational theory, as existing in the 1960's as an expression of weberian instrumental rationality. Utilizing Amitai Etzioni ideas it tries to fathom the gap between western and non western societies. The core of the argument states that western societies, by their own historical formation ended by exhibiting conditions by far more congenial and adequate for the nurturing, development and operation of formal organizations as an expression of instrumental rationality. Thus formal organizational requirements would be of a society displaying ability to subordinate individual to social interests, adoption of a pragmatic epistemological posture, a behaviour based upon emotional neutrality and capacity of objectification through organized action. Non western societies do not have yet, due to their own history and formative process, the same conditions.

Thus a greater difficulty, in nurturing and developing formal organizations what end sup in the vicious circle of low organizational density.

* KEY WORDS: Formal organization, instrumental rationality, functional and structural analysis, western societies. 


\section{INTRODUÇÃO}

O que nos levou a escrever este artigo foram algumas reflexões sobre a Teoria das Organizações quando colocada em face da realidade brasileira, ou, de maneira mais ampla, quando tentamos utilizar um "modelo" originado numa realidade cultural diversa daquela em que vivemos e somos obrigados a agir. Já têm sido feitas observações a respeito da inadequação da teoria econômica clássica, enquanto elemento explicativo da realidade não ocidental. Recentemente, chegou-se até a falar da inadequação do marxismo enquanto gerador de ideologias para países da África e a pequena aceitação que as idéias marxistas desfrutavam entre os próprios líderes africanos, pois que, sendo o marxismo um conjunto de idéias oriundas da Europa Ocidental e surgindo num momento de relativa sofisticação dialética, em muito pouco poderia corresponder aos anseios, necessidades e desejos de autoafirmação de comunidades negras ainda primitivas $e$ recém emancipadas, e que buscam um estatuto ideológico a fim de fundamentar sua ação política no conjunto das nações independentes.

A Teoria das Organizações vem se consolidando, enquanto disciplina autônoma, principalmente nos Estados Unidos e tem resultado do esforço de estudiosos com a mais diversificada formação cultural. É possível relacionar entre os "teóri$\cos ^{\prime \prime}$ da Organização sociólogos, psicólogos, matemáticos, economistas e biólogos. E inevitável que tentem aplicar às suas reflexões os modelos e conceitos fundamentais das ciências em que foram formados, o que explica o caráter eclético e pouco orgânico da Teoria das Organizações na sua fase inicial. Porém todos estes elementos apesar de sua diversidade contêm, a nosso ver, alguns elementos em comum que poderiam ser resumidos sob a elevada racionalidade atingida pelas sociedades ocidentais nos últimos quatro séculos. Foi esta racionalidade e particularmente o desenvolvimento das ciências sociais, e dentre elas, a economia, as responsáveis pelo oferecimento de um quadro conceitual altamente elaborado e dotado de suficiente operacionalidade que permitiu a todos os teorizadores a formulação de uma Teoria das Organizações.
Ora, considerando-se que os países não desenvolvidos, o que equivale a dizer nãoocidentais de um ponto de vista cultural (a União Soviética é, em nosso entender, um país permeado de cultura ocidental, o que se tornou definitivo após a revolução de 1917), não têm o mesmo passado que os países ocidentais, e suas culturas se afastam, por vezes, diametralmente dos padrões de racionalidade, tal qual esta é entendida na cultura ocidental, cabe questionar da validade da Teoria das Organizações quando aplicadas a um contexto diverso do ocidental.

Portanto, propomo-nos desenvolver este artigo em quatro etapas:

- As teorias de organização como ex pressão da racionalidade.

- O significado dessa racionalidade.

- Exigências organizacionais e

- Conclusão.

\section{AS TEORIAS DE ORGANIZAÇÃO COMO EXPRESSÃO DA RACIONALIDADE}

As primeiras tentativas no sentido de elaborar uma teoria organizacional tiveram lugar nos Estados Unidos, na Inglaterra e na França e, considerando-se a disputa que se tem desenvolvido entre os especialistas, decidimos não nos deter na determinação de quem teria sido realmente o primeiro a formular um conjunto de idéias a respeito das organizações. Conseqüentemente nos ateremos às doutrinas de Frederick W. Taylor e Henri Fayol como os teorizadores que exerceram influência decisiva na formação de uma teoria que já nos habituamos a chamar de clássica.

O que importa considerar do nosso ponto de vista não são as várias medidas de racionalização do trabalho empreendidas por Taylor ou a enumeração de "funções" administrativas realizadas por Fayol, mas antes nos determos sobre os procedimentos metodológicos e os pressupostos de uma filosofia da ciência, que permeavam as etapas da elaboração das teorias dos referidos pensadores. Acreditamos que a "escola clássica" foi a manifestação de uma racionalidade de tipo baconiano e cartesiano ao nível da teoria da organização. O próprio Taylor lamentava diante da Comissão de Inquérito, instaurada para investigar os efeitos e conseqüências do 
taylorismo sobre o regime de trabalho operário em algumas organizações americanas por volta de 1912, o desperdício em que se incorria por causa da ineficiência industrial que acarretava enormes prejuízos à nação, retardando o seu ritmo de desenvolvimento. Esta ineficiência, no entender de Taylor, era motivada pela falta de uma ciência da administração que permitisse a objetivação dos procedimentos e a constituição de um corpo de conhecimentos que dessem à administração as mesmas características de universalidade encontradiças em outros setores do conhecimento e da atividade humana. A ausência de uma "verdade" administrativa implicava em que se dependesse para a condução das empresas dos "homens de gênio", cuja incidência e aparecimento eram aleatórios.

A criação de uma categoria especial, os administradores profissionais, só seria possível quando se consolidasse um "conjunto de princípios" à maneira do que acontecia com outras atividades, tal como na medicina, no direito, na matemática, para citar apenas alguns exemplos. A consolidação de um conjunto de conhecimentos, que se faria de maneira ordenada e segundo uma metodologia adequada ao objeto em estudo, permitiria não apenas a acumulação de conhecimentos, bem como a sua transmissão através de um processo formal de educação. E esta transmissão de conhecimentos de maneira sistemática, rotinizaria, de certa forma, o processo de criação de habilidades administrativas, eliminando a contingência em que então acreditava Taylor - todos se encontravam com relação ao "homem de gênio", o que implicava na crença de que o administrador não podia ser formado, pois as suas habilidades seriam o resultado misterioso de capacidades inatas que se desenvolveriam mediante a prática. Quando se tratou de buscar uma forma de criar uma "ciência da administração", Taylor voltou-se, mais por intuição do que por reflexão, à utilização da já tradicional metodologia da ciência que há três séculos vinha se mostrando frutífera no campo das ciências da natureza. A "revolução" do espírito científico na idade moderna tivera lugar graças à contribuição decisiva de Francis Bacon, Galileo Galilei e René Descartes. O que aqueles pensadores realizaram foi a trans- formação radical da própria concepção de ciência, bem como de sua finalidade, sendo abandonada a noção de ciência, enquanto atividade especulativa, o que vale dizer contemplativa, que dominara o pensamento ocidental desde a antiguidade clássica até os fins da Idade Média, para substituí-la por uma concepção de ciência enquanto instrumento ativo para possibilitar a extensão do domínio do homem sobre os fenômenos da natureza.

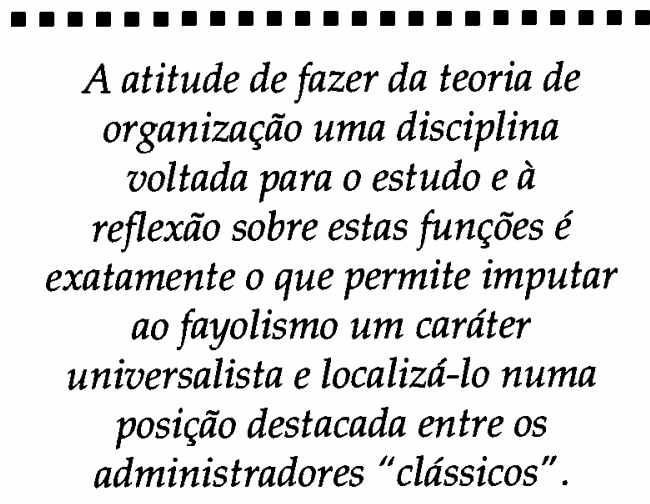

$A$ atitude de fazer da teoria de organização uma disciplina voltada para o estudo è̀ reflexão sobre estas funções é exatamente o que permite imputar ao fayolismo um caráter universalista e localizá-lo numa posição destacada entre os administradores "clássicos".

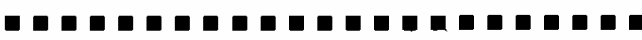

A ciência deveria possibilitar o entendimento dos fenômenos naturais para que estes pudessem ser explicados, verificados e previstos, objetivando-se ao final o seu controle. A utilização dos resutados da matemática, como instrumento para expressar quantitativamente os referidos fenômenos, foi um passo decisivo, pois, ao expressar-se quantitativamente um fenômeno, nós automaticamente lhe imputamos um caráter mecânico e repetitivo, o que permite, em conseqüência, prevê-lo e, em última instância, controlá-lo.

As etapas desse método são bastante conhecidas, porém não cremos impróprio assinalá-las. Num primeiro momento, temos a observação, que, todavia, não é mais realizada de maneira puramente contemplativa, mas pressupõe uma atitude crítica da inteligência ao caracterizar o que deve ser observado. Um segundo momento é o de elaboração de hipótese. $O$ terceiro momento é aquele em que as hipóteses são verificadas e, dependendo do resultado dessa verificação, elas passam a ser consideradas verdadeiras ou falsas e na primeira alternativa são incorporadas a um conjunto de conhecimentos que possibilitem a construção de teorias mais amplas.

Na verdade, o taylorismo na sua busca 
da one best way partia do pressuposto de que existia uma verdade implícita na maneira de se fazerem as coisas e constituía a tarefa da razão a sua descoberta. Apesar de Taylor ter-se tornado particularmente célebre como o criador dos estudos de "tempos e movimentos", cumpre notar que os tempos e movimentos não constituíam, como ele mesmo assinalou várias vezes, $o$ ponto central de suas idéias. Constituíam antes um meio de racionalizar o trabalho humano e um instrumento de verificação, análogo aos métodos de medição utilizados na etapa de observação para as ciências da natureza. A Escola Clássica de administração caracterizou-se por aplicar à realidade industrial, dos fins do século passado e princípios de nosso século, os mesmos procedimentos e o mesmo quadro conceitual que se havia provado de grande valia e, inclusive, permitindo um grande desenvolvimento das ciências da natureza.

A necessidade de "transformação de mentalidade", que Taylor chega a propor como definição final e a mais adequada para o movimento da "administração científica" (scientific management), não seria mais do que a aceitação de que a administração deveria tornar-se um campo de conhecimento tão científico, como a realidade da natureza já se tornara para as ciências de tipo físico-matemático, e que seria forçosamente passível sua transformação numa ciência quantificável, onde se encontraria uma verdade definitiva, à maneira matemática, e que tal seria fatalmente alcançado, sendo apenas uma questão de tempo.

O quadro de uma ciência da administração, como visto pelo francês $\mathrm{H}$. Fayol, não divergia em suas idéias gerais do que havia sido tentado por Taylor. É mister reconhecer, contudo, que Fayol é, indiscutivelmente, o nível mais elevado quando se cogita esse assunto. Sempre se notara que as formulações de Taylor permaneceram a nível de fábrica, sendo tal afirmação particularmente verdadeira para o seu livro Shop Management, publicado em 1906. O Principles of Scientific Management, apesar do caráter ponposo de seu título, não introduz grandes inovações quando comparado com a obra anterior, e a mesma sensação de que se permanece ao nível de fábrica persiste. Já não é possível fazer as mesmas afirmações a respeito de $\mathrm{H}$. Fayol.
Sua obra Administração Geral e Industrial, cuja primeira edição data de 1916 , contém elementos que nos colocam claramente noutro nível administrativo, ou seja, a administração de cúpula. Não encontramos no fayolismo a preocupação com a "racionalização" de tarefas e os estudos de "tempos e movimentos" que constituem o traço distintivo e ocupam a maior parte das obras de Taylor. Nada de propriamente operacional, ou a nível de execução de tarefas, é abordado pelo industrial francês, $e$ suas preocupações voltam-se no sentido de abstrair a partir de um grande número de tarefas, forçosamente heterogêneas, aquelas que seriam propriamente administrativas e que conseqüentemente seriam atribuição específica do administrador. Daí poder qualificar-se Fayol como um funcionalista, pois sua preocupação fundamental foi conseguir agrupar as tarefas essencialmente administrativas desempenhadas pelas pessoas no interior das organizações e dar-lhes o nome de funções. O que estas possuem de mais característico é o seu afastamento com relação ao rotineiro das organizações. $\mathrm{O}$ administrador para Fayol é justamente aquele que não se dedica à realização de tarefas rotineiras e, em resumo, aquele que não se deixa absorver pela operação da empresa.

A atitude de fazer da teoria de organização uma disciplina voltada para o estudo e à reflexão sobre estas funções é exatamente o que permite imputar ao fayolismo um caráter universalista e localizá-lo numa posição destacada entre os administradores "clássicos". A identificação entre a ciência da administração e a teoria das funções administrativas é que dá ao fayolismo o seu caráter de tentativa científica, na medida em que tenta reduzir a multiplicidade à unidade, ou pelo menos tenta introduzir um ordenamento racional ao real singular e até certo ponto caótico.

Não cremos que as demais "escolas" de administração tenham se afastado deste sentido da racionalidade até o momento apontado. As experiências e teorias de G. Elton Mayo e de seus seguidores, do chamado grupo das Relações Humanas não negaram a necessidade da racionalidade na esfera da administração, mas antes se satisfizeram em apontar algumas limitações dos teóricos anteriores, sem todavia contestar-lhes os fundamentos. O próprio 
Mayo em seu último livro The Social Problems of an Industrial Civilization, ao avançar uma explicação sobre as causas de não se terem desenvolvido em nossa civilização industrial as "habilidades sociais" (social skills) com a mesma intensidade com que se desenvolveram as "habilidades técnicas" (technical skills), acaba por deplorar o estágio em que se encontravam as ciências sociais, devido, em última instância, ao fato de não terem logrado realizar ainda a "revolução científica" que as ciências da natureza haviam realizado no início da Idade Moderna. As "habilidades técnicas" se transformaram no traço predominante da civilização ocidental, através de sua industrialização e do domínio da natureza pela tecnologia, porque as ciências da natureza haviam se limitado a atacar pontos específicos do real e em conseqüência tornaram possível a "operacionalidade" neste setor do conhecimento e da atividade humanos. O mesmo ainda não havia sucedido com as ciências sociais que permanecia presas a um passado ainda de pura especulação, sendo mais uma "filosofia social" do que uma ciência social.

A atividade econômica anterior ao
capitalismo desconheceu, de maneira
geral, a empresa, enquanto entidade
de duração indefinida,
preferivelmente permanente, cuja
missão fundamental era realizar a
mais-valia e dessa forma prosseguir
indefinidamente a dominação da
natureza pelo homem através do
reinvestimento e do aperfeiçoamento
tecnológico ilimitado.

Acreditamos desnecessário estendernos sobre a alta racionalidade que preside às especulações de tendências mais recentes no campo da Teoria da Organização. A tentativa de aplicação de modelos matemáticos e de técnicas bastante sofisticadas, tomadas às ciências sociais, são prova suficiente de uma racionalidade crescente $e$ cada vez mais exigente para a formulação teórica.
Porém, não poderíamos deixar de mencionar a teoria weberiana da burocracia quando nos referimos à racionalidade que tem presidido à elaboração das várias teorias de organização. A elaboração do sociólogo alemão é sobremaneira interessante pelo fato de Weber não ter sido um intelectual especialmente preocupado com os problemas da prática administrativa. Diríamos que a abordagem weberiana ao problema das grandes organizações, inclusive as de natureza econômica, não tinha por objetivo o aumento da eficácia, como sempre ocorreu com a grande maioria dos estudiosos. Em autores como Taylor, Fayol e E. Mayo, este constitui o objetivo fundamental. $\mathrm{O}$ aumento da produtividade industrial com a eliminação da ineficiência e dos atritos - particularmente de natureza humana que dificultam o andamento dos procedimentos administrativos - sempre foi a causa fundamental de suas pesquisas, reflexões e recomendações. O mesmo não ocorreu com Max Weber teórico preocupado fundamentalmente em explicar uma situação histórica que foi atingida pela cultura ocidental num dado momento. Weber chega à teoria da organização pelo que ousaríamos chamar de via política. Ao estudar as transformações econômicas, políticas e sociais da sociedade ocidental a partir da Idade Média, Weber não pode deixar de fascinar-se pela importância que gradativamente veio assumindo o Estado até atingir sua atual fisionomia. O Estado como centralizador de poder e responsável pela manutenção da soberania, o que implicava no controle de uma determinada área geográfica e no estabelecimento de uma estrutura jurídica, viu-se forçado a criar uma superestrutura administrativa para administrar a coleta dos recursos com que sustentar forças armadas de caráter permanente e manter os quadros administrativos não militares para implementação dos ordenamentos jurídicos. Isto levou à criação de uma "máquina administrativa" ou "burocracia" que se caracteriza, antes de mais nada, pela sua "profissionalização". O que deve caracterizar um "corpo de funcionários" é a sua dedicação a tarefas específicas, de natureza razoavelmente complexa, que pressupõe um treinamento adquirido através de um processo formal de educação e que transforma o administrar numa "profis- 
são" que se desempenha mediante o pagamento de salários e modalidades várias de benefícios e que confere aos administradores "estabilidade", como dimensão temporal, a fim de assegurar a própria continuidade da "burocracia".

A "burocracia" é indiscutivelmente uma formulação ideal e o próprio Weber já a reconhecia como tal, mas isto não significa o seu desvinculamento da realidade, uma vez que o responsável pela sua elaboração partiu de um dado histórico concreto, a saber, as grandes estruturas da "administração pública", que acompanharam o desenvolvimento do moderno Estado Ocidental. O que torna a teoria weberiana digna de interesse para o moderno teórico das organizações, bem como para o administrador prático, é a sua irrefutável atualidade, que se deu graças ao grande desenvolvimento atingido pela moderna empresa industrial no sistema do capitalismo e que é particularmente perceptível na moderna sociedade anônima com a diluição da propriedade por um grande número de acionistas, implicando numa modificação real do tradicional conceito de propriedade privada e pela complexidade de suas operações e pelo seu porte que freqüentemente atinge dimensões internacionais.

Se retomarmos as afirmações de Weber, a respeito da importância de um direito abstrato e genérico, que tornou possível o Estado Ocidental Moderno, e que "burocracia" é a estrutura criada para dar aplicação à racionalidade abstrata contida nas normas jurídicas, desnecessário será estendermo-nos sobre o caráter altamente racional da administração burocrática.

"A administração burocrática significa, fundamentalmente, o exercício da dominação baseada no saber. Este é o traço que a torna especificamente racional. Consiste, de um lado, em conhecimento técnico que, por si só, é suficiente para garantir uma posição de extraordinário poder para a burocracia. Por outro lado, deve-se considerar que as organizações burocráticas, ou os detentores do poder que dela se servem, tendem a tornar-se mais poderosos ainda pelo conhecimento proveniente da prática que adquirem no serviço" ${ }^{1}$ E no que diz respeito à racionalidade da empresa capitalista e à inevitabilidade da adoção da administração de tipo burocrático para a condução dos afazeres empresariais cum- pre observar que "... a burocracia é superior em saber ... o que normalmente é privilégio da empresa capitalista."

O texto weberiano ainda fazia distinção entre empresa capitalista e forma burocrática de administração. Não se deve deixar de considerar que o capitalismo dos fins do século e das primeiras décadas de nosso século ainda se caracterizava fundamentalmente pelo livre empresarialismo, e o planejamento, bem como os demais ingredientes de uma administração burocrática estavam fundamentalmente vinculados à administração pública, ou seja, ao Estado. Mas com o fim do "empresário schumpeteriano" - que acreditamos ser um personagem já histórico, e cujo reaparecimento se torna cada vez menos possível - a empresa capitalista foi gradativamente assumindo as mesmas características decisivas da administração burocrática.

\section{O SENTIDO DA RACIONALIDADE}

Nas páginas anteriores já tivemos oportunidade de esboçar o que se deveria entender por racionalidade. Acreditamos que se trata de conceito exclusivo da cultura ocidental e de origem relativamente recente. A racionalidade, no sentido em que hoje a tomamos, não tem mais do que cinco séculos e seu nascimento está ligado à Revolução Filosófico-Científica que teve lugar na Europa ao longo dos séculos XVI e XVII. Já mencionamos que sua origem poderia ser localizada no novo conceito de ciência, expresso pela primeira vez, por Francis Bacon no seu Novum Organon. A tradição grega, que a Idade Média cristã incorporou, via na razão o instrumento para a aquisição de um saber destinado exclusivamente à satisfação do sujeito cognoscente e que deveria conduzir à contemplação. $O$ ideal foi apresentado de maneira relativamente clara no pensamento platônico, e grande parte dos "ideais de vida" da cristandade medieval não são mais do que a sua versão revestida de um caráter evangélico. A razão deveria aplicar-se ao conhecimento das coisas, mas sempre como mediação para o conhecimento das coisas divinas. Daí a inexistência de uma concepção de "vocação", no sentido weberiano, enquanto "chamamento" para a realização com todo o empenho e
1. "TEXTOS Básicos de Ciências Sociais". Sociologia da Burocracia. Rio de Janeiro, GB, Zahar Editores, 1966, p. 26

2. Idem, ibidem, p. 26. 
energia de uma tarefa neste mundo, como por exemplo o desempenho de uma profissão laica. Esse aspecto já foi suficientemente desenvolvido pelo próprio Weber em seu livro sobre a ética protestante $e$ as suas relações com o aparecimento de uma mentalidade capitalista e não julgamos necessário entrar em pormenores.

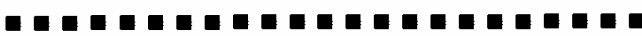

$A$ "debilidade organizacional" de sociedades não ocidentais é em grande parte devida a uma ênfase excessiva dada ao indivíduo e à tentativa de fazer prevalecer, no quadro de valores éticos, os princípios da individualidade, onde o sucesso ou a valorização são dados em última instância por uma medida individual de sucesso.

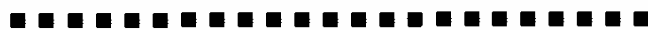

Um dos atributos da racionalidade é a logicidade, definida no sentido formal e material, ou seja, a coerência da inteligência consigo mesma ao longo do processo de conhecimento e a sua adaptação ou adequação a uma realidade exterior a esta própria inteligência. Todo ato de investigação que pretenda atingir algum conhecimento assume implicitamente um paralelismo entre o sujeito que conhece e o objeto de conhecimento. É exatamente neste paralelismo que está a possibilidade de conhecimento. Tal atitude da racionalidade não constituiu um atributo específico dos tempos modernos, uma vez que toda a filosofia e toda a ciência grega e medieval dela já faziam extenso uso, inclusive chegaram a teorizar sobre o problema de maneira exaustiva.

O que é típico da racionalidade moderna é a sua preocupação com utilizar a logicidade para dominar a realidade exterior ao homem, particularmente as forças da natureza. O desenvolvimento da moderna Economia Política sempre considerou a economia como a ciência que cuidava das atividades desempenhadas pelo homem no sentido de transformar os recursos brutos ou naturais em bens econômicos que pudessem ser utilizados para a manutenção da vida humana e para au- mentar o conforto. É a preocupação em refinar e fazer progredir sempre as formas e instrumentos de domínio do homem sobre a natureza que preside ao aparecimento e ao posterior desenvolvimento de toda a tecnologia. Dentre as Teorias de Organização, a de Chester Barnard é a que carrega traços mais fortes deste tipo de concepção, e a sua teoria da cooperação como pressuposto para o aparecimento das "organizações formais" está sempre fundamentada na necessidade de reunir esforços e criar "sistemas cooperativos" a fim de superar as limitações "físicas" e "biológicas" à consecução de objetivos grupais.

Todavia, a logicidade e a aplicação da inteligência à modificação da realidade exterior não constituem os únicos atributos da racionalidade. Na verdade, é impossível desvinculá-la da eficácia, enquanto parte inseparável de um determinado sistema de produção, o que constitui a marca distintiva da racionalidade num mundo em que predomina o modo industrial de produção.

A aplicação da razão à produção de bens econômicos constitui o traço predominante da Revolução Industrial. O antigo sistema artesanal já havia indiscutivelmente introduzido algumas modificações no sentido de aumentar a sua produtividade. Exemplo bastante conhecido é o que teve lugar na produção de livros. Durante a Idade Média, os copistas dedicavam-se à paciente e minuciosa tarefa de preservar e transmitir às gerações posteriores o conhecimento acumulado. Cada copista ocupava-se da elaboração de um único exemplar que era feito a partir de um original. Já no século XIV e XV, vários copistas escreviam vários exemplares a partir de uma outra pessoa que lia em voz alta. Isto, porém, ainda se achava bastante distante do sistema de produção em massa que só se tornou possível com a criação dos tipos móveis. Além disso, a racionalidade, enquanto busca da eficácia de um sistema de produção em massa, relaciona-se diretamente com a racionalidade própria do capital, que tem suas próprias leis.

A explicação do crescimento econômico oferecida pelos economistas clássicos, ou de expansão do capital, no entender de alguns marxistas, particularmente Rosa de Luxemburgo, reveste-se de uma racionalidade que nunca foi atingida pela ati- 
vidade econômica em outras épocas da história. É por isso que o termo capitalismo, quando aplicado a outros períodos históricos, especificamente ao comércio fenício ou grego, só pode ter um sentido analógico, pois o que distingue o capital é a necessidade de realização da mais-valia, que só pode ser entendida como forma de um domínio progressivo sobre a natureza. A atividade econômica anterior ao capitalismo desconheceu, de maneira geral, a empresa, enquanto entidade de duração indefinida, preferivelmente permanente, cuja missão fundamental era realizar a mais-valia e dessa forma prosseguir indefinidamente a dominação da natureza pelo homem através do reinvestimento e do aperfeiçoamento tecnológico ilimitado.

As atividades econômicas pré-capitalistas, ou anteriores ao sistema capitalista, satisfaziam-se com a realização de um adicional que deveria ser propriedade dos que haviam contribuído com o principal, $\mathrm{e}$ que poderiam utilizar como bem lhes aprouvesse. A idéia de empresa como going concern, cuja missão é reinvestir, crescer, desenvolver-se tecnologicamente $e$ expandir-se, avançando contra o pré-capitalismo que a cerca, constitui marca indiscutível de sua racionalidade.

O fato de que a expansão é intrínseca ao capital e que esta só poderá ser feita na medida em que o capital for capaz de multiplicar-se, implica na necessidade de buscar a eficácia e os conseqüentes aumentos de produtividade do sistema, seja do equipamento (bens de capital) ou da mão-de-obra. É apenas pela realização de uma margem de lucro cada vez maior que será possível assegurar um reinvestimento crescente para consecução da expansão.

\section{AS SOCIEDADES SUBDESENVOLVIDAS}

O termo é imperdoavelmente genérico e certamente exige uma explicação. Todavia, não é por acaso que as sociedades que se desenvolveram economicamente foram as de cultura ocidental ou aquelas que adotaram a cultura do ocidente. Por enquanto, o único exemplo de sociedade não ocidental que teria logrado o desenvolvimento seria o Japão, e mesmo assim não creio que possamos ter como certo que o Japão não acabe por render-se aos padrões ocidentais, à medida que o seu enriqueci- mento aumente. Somos tentados a afirmar que as áreas não desenvolvidas do ocidente são exatamente as que, apesar de estarem inseridas geograficamente no mundo ocidental, se afastam em órbitas diversas a partir dos valores centrais desta cultura.

Portanto, não seria exagero afirmar que até o momento o desenvolvimento econômico tem sido atributo das sociedades ocidentais, ou das que adotaram, de uma forma ou de outra, o quadro de referências vigente no ocidente. A constatação recente de Robert Heilbronner de que após a Revolução Industrial os únicos países que lograram desenvolver-se foram os que adotaram o regime comunista ${ }^{3}$, é uma prova irrefutável da ocidentalização destas culturas. Evidentemente o futuro poderá introduzir modificações não previsíveis, como o de um marxismo altamente sinificado, como parece estar ocorrendo com o pensamento de Mao-Tse-Tung - o que seria um afastamento dos padrões ocidentais que constituem os fundamentos do marxismo.

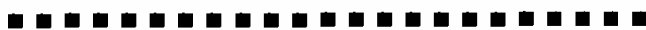 \\ Se considerarmos que o aparecimento de organizações formais é a forma social mais adequada para a realização da racionalidade, torna-se facilmente inteligivel porque as sociedades não desenvolvidas são as que padecem de maior fraqueza organizacional.}

De maneira geral, as sociedades não desenvolvidas, e por tal entenderíamos as que ainda não lograram uma renda real per capita razoável, são em geral não industrializadas, ou nelas a indústria desempenha um papel secundário, enquanto componente do Produto Interno, com o predomínio da agricultura em formas tradicionais, tanto no que diz respeito às técnicas de produção empregadas, como à distribuição do espaço arável. Aqui a agricultura representa o modo tradicional de vida, e faz parte do ethos que nela lança profundamente suas raízes, a ponto de se poder falar em ethos urbano e ethos rural para distinguir sociedades em que a
3. HEILBRONNER, Robert. Commentary, abril de 1967. 
indústria ou a agricultura nas suas formas tradicionais, determinam os valores da sociedade global. Estas sociedades não partilham das concepções do ocidente e suas "visões do mundo" são fatalmente diversas das vigentes no ocidente. Os seus valores variam enormemente de região para região e mesmo de país para país, que qualquer tentativa de generalização incorreria forçosamente numa simplificação perigosa e não respeitaria as peculiaridades de cada cultura.

Todos os atributos da racionalidade descritos anteriormente não são encontrados nestas culturas e, quando existe, são de origem recente, introduzidos de várias formas. Já se pretendeu demonstrar, que a industrialização pode ser obra de vários tipos de elites. E interessante consultar sobre este ponto o livro de Kerr, Dunlop, Harbison e Myers, Industrialism and Industrial Man, onde o assunto é exposto com grande precisão e de maneira bem ordenada. Entretanto, não importa quem realize a industrialização, uma elite militar, um grupo nacionalista fortemente imbuído de sentimentos xenóforos, uma minoria de intelectuais, ou uma classe marginalizada no sistema social vigente, como podem ser os comerciantes em muitas sociedades não desenvolvidas de hoje, ou como o foi a burguesia no contexto europeu moderno: importa é que qualquer que seja o grupo realizador da industrialização, ele estará inovando, exatamente porque pretende impor à sua sociedade um quadro de valores e formulando objetivos estranhos ao que há de mais profundo em suas culturas, destoante da "visão do mundo" dos ancestrais, e que em muito se aproxima da racionalidade inerente ao modo de produção industrial ocidental. O fato de estas elites industrializadoras, para usar a própria terminologia dos autores citados, terem sido profundamente marcadas por uma "experiência ocidental" constitui dado suficiente para o ponto que estamos apresentando. Estas experiências seriam observáveis no caso de membros da sociedade que tiveram a oportunidade de receber um treinamento formal em sistemas universitários europeus, no período do "colonialismo", como foi o caso de grande parte dos atuais dirigentes hindus, ou como hoje é o caso de grande parte de membros de ex-colônias, que ainda não dispõem de um sistema universitário capaz de formar mão-de-obra altamente qualificada, ou que simplesmente não possuem nenhum sistema universitário e que enviam parte de seus jovens para que se graduem nos Estados Unidos, na Europa ou na União Soviética. Estes grupos poderão ou não vir a ocupar o núcleo de poder nestas sociedades, mas sempre acabarão por ser inovadores na medida em que não poderão deixar de transmitir aos seus concidadãos as suas experiências significativas. Estamos certos de que serão com maior ou menor sucesso instrumentos "racionalizadores" de suas respectivas sociedades.

Se considerarmos que o aparecimento de organizações formais é a forma social mais adequada para a realização da racionalidade, torna-se facilmente inteligivel porque as sociedades não desenvolvidas são as que padecem de maior fraqueza organizacional nos vários níveis, seja na sociedade civil e nas suas manifestações econômicas, seja a nível governamental. Daí, o paradoxo de que estas sociedades necessitam realizar um grande esforço em direção à organização para poder romper a estagnação e ao mesmo tempo só poderem organizar-se na medida em que adotarem um mínimo de racionalidade em seus comportamentos.

\section{EXIGÊNCIAS ORGANIZACIONAIS}

A vida organizacional implica uma grande abstração, em conceitos gerais só perceptiveis através de uma grande sofisticação de pensamento que são pouco encontradiços nas sociedades não desenvolvidas. As exigências da vida organizacional poderiam ser sumariadas nos seguintes tópicos:

I - Subordinação do interesse individual ao interesse geral. $\mathrm{Na}$ verdade, não estamos afirmando o truímo de que o homem é naturalmente organizado e que a vida em organização constitui uma aspiração fundamental de sua natureza. A teoria do homem "animal político" é ingênua e não poderia ser repetida após tantas e amargas experiências de conflito entre interesses individuais e organizacionais. O choque entre valores e aspirações individuais e os objetivos formais de 
uma organização já tem sido objeto de excelentes estudos e não nos deteremos mais sobre o assunto. $O$ comportamento não perfeitamente ajustado (deviant behavior) pode assumir várias formas, e não existe uma adaptação perfeita entre objetivos individuais e organizacionais, porém, mesmo que se conceda uma margem relativamente elástica de tolerância, sempre será necessário um certo conformismo individual aos padrões e objetivos da organização.

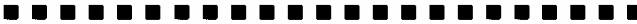 \\ A crença de que é possível modificar a realidade econômica e social por obra legislativa é uma falácia de que muitas sociedades ainda não conseguiram se desvencilhar. Ainda encerra um certo grau de "pensamento mágico" ao pressupor que a ordem jurídica "cria" uma realidade econômica, política e social nova.}

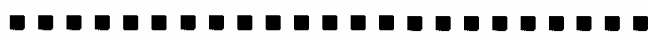

A esta altura torna-se inevitável que nos adentremos no problema do indivíduo, enquanto membro de organizações formais. $\mathrm{O}$ assunto tem sido tratado por especialistas americanos e europeus e cremos que algumas observações devem ser feitas quanto à sua aplicação a países não ocidentais. Acreditamos que a lacuna entre os padrões e referências para o comportamento individual ou os valores da organização informal estão nas sociedades ocidentais muito mais próximos dos objetivos de uma organização formal do que entre outras sociedades. Não podemos deixar de relacionar a vida organizacional com uma sociedade de massas, ou seja, onde o resultado da interação social já prepara o indivíduo para integrar-se nas organizações formais. Hester Barnard, ao tratar da possível contribuição dos fatores psicológicos e sociais para a formação de sistemas de cooperação, conclui que o resultado da interação de indivíduos é o dado fundamental para que se chegue ou não a um sistema de cooperação $0^{4}$, de onde cabe inferir que são as formas de socialização que ocorrem a nível dos grupos primários em grande parte responsáveis pela ten- dência a uma integração eficiente do indivíduo, enquanto membro de uma organização formal. Tal forma de interação deverá, inevitavelmente, moldar valores mais gerais do que particulares na personalidade básica de uma comunidade e será uma forma de interação que oferecerá poucas oportunidades para o florescimento de tendências individualistas.

A "debilidade organizacional" de sociedades não ocidentais é em grande parte devida a uma ênfase excessiva dada ao indivíduo e à tentativa de fazer prevalecer, no quadro de valores éticos, os princípios da individualidade, onde o sucesso ou a valorização são dados em última instância por uma medida individual de sucesso.

Exemplificando nossa afirmação - de que a lacuna entre a sociedade com os seus respectivos padrões e, conseqüentemente, os objetivos e valores da organização informal não se distanciaram fundamentalmente das metas da organização formal nas sociedades ocidentais - faríamos referência ao célebre estudo de Max Weber sobre o protestantismo e as origens do espírito capitalista em alguns países da Europa Ocidental e nos Estados Unidos. A laicização do significado da vocação (call, beruf), que se fez graças à ética protestante e dentre as várias seitas, particularmente o calvinismo, foi responsável pela formação de uma "consciência verbal" que os predispunha a uma certa neutralidade afetiva, a uma busca de realização de uma vocação, especialmente em termos profissionais e a uma tentativa de trabalhar arduamente, sem expectativa de uma compensação imediata, que em muito prepararam o advento e o estabelecimento de objetivos organizacionais, tais quais são definidos para as grandes organizações de tipo burocrático que, posteriormente, surgiram.

A idéia de uma vocação (call, beruf), em termos weberianos, ou a existência de um propósito organizacionalmente realizável, não é uma formulação encontradiça nas sociedades não ocidentais, onde prevalece o individualismo, o fatalismo ou uma indiferença mística que conduz a um fatalismo em muitas sociedades no tocante a realizações profissionais que levem a uma transformação da realidade exterior.

II - Adesão a uma filosofia do conhecimento que envolva o pragmatismo. Ou-
4. BARNARD, Chester. The Functions of the Executive. Oxtord, Harvard University Press, 1936. 
tra exigência é a adesão a uma filosofia do conhecimento que envolva o pragmatismo. A concepção que as sociedades não ocidentais possuem do conhecimento é em grande parte de natureza puramente especulativa, onde o ato de conhecer é um fim em si mesmo e por si plenamente justificável.

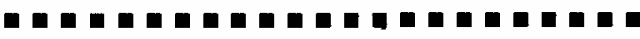 \\ Numa sociedade como a brasileira, as organizações estão quase sempre permeadas de relações que têm sua origem em relações familiares ou de amizade. Ainda é grande a insegurança que se apossa das pessoas quando têm de estabelecer relacionamento formal, onde as relações de tipo simpático deixam de existir, e o primado deve pertencer à norma geral e abstrata.}

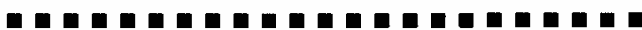

A concepção pragmática do conhecimento envolve um relacionamento entre sujeito e objeto de conhecimento que não se satisfaz e não termina com a adequação entre sujeito e objeto de conhecimento no ato de conhecimento, mas prossiga indo buscar a validação na esfera da práxis.

O pragmatismo, enquanto posição referente à teoria do conhecimento, deve ser entendido como validação em função da ação. Este foi o sentido dos moralistas ingleses do século passado, particularmente John Stuart Mill e Jeremy Bentham, que foram os responsáveis pela nova formulação sobre a finalidade e a validação do conhecimento em nossos dias.

A concepção pragmática será capaz de despertar uma outra atitude intelectual por meio da qual todos os esforços da inteligência convergiriam para um ideal de realização e de eficácia.

Ao pragmatismo aborrece a grande construção sistemática, feita exclusivamente em nome da coerência e do formalismo lógico, se tal sistematização não se prestar a uma aplicação concreta tendente a modificar a realidade exterior. $O$ desenvolvimento tecnológico que assume dimensões cada vez mais assombrosas tem sido em grande parte o resultado de uma visão pragmática do processo de conhecimento e no abandono da distinção entre teoria e prática, ou entre ciência pura e aplicada para a elaboração de uma síntese em que a teorização é vista como parte inseparável de um único processo que é o de modificação da realidade.

As grandes construções verbais que se traduzem nos códigos de uma legislação positiva constituem uma das formas que pode assumir a elaboração intelectual numa cultura em que o pragmatismo ainda não penetrou. A paixão da casuística que conduz à jurisprudência é uma destas manifestações. A crença de que é possível modificar a realidade econômica e social por obra legislativa é uma falácia de que muitas sociedades ainda não conseguiram se desvencilhar. Ainda encerra um certo grau de "pensamento mágico" ao pressupor que a ordem jurídica "cria" uma realidade econômica, política e social nova.

III - Neutralidade afetiva. A vida organizacional pressupõe a adoção de modos de comportamento fundamentados na "neutralidade afetiva". A hierarquização, a designação de pessoas para o cumprimento de determinadas tarefas, a estabilidade inevitavelmente associada ao ocupante do cargo, o relacionamento das pessoas em função de suas posições e das tarefas que devem cumprir fazem com que a organização de tipo formal obrigue os seus membros a não levarem em conta $o$ "amor" ou o "ódio", enquanto móvel de suas ações. $O$ relacionamento puramente afetivo transforma-se quase inevitavelmente numa fonte de ineficácia organizacional, pois que permite a introdução de distorções, tais como a quebra de objetividade nos procedimentos administrativos abrindo campo para práticas igualmente patológicas do ponto de vista organizacional, como o "favoritismo" ou a "discriminação". "A estrutura (burocrática) se aproximará da eliminação completa das relaçōes pessoais e das considerações não racionais (hostilidade, ansiedade, envolvimentos afetivos, etc. $)^{55}$

Tal formulação encontraria restrições em nossos dias em trabalho levado a cabo por David McClelland em seu livro The Achieving Society onde são buscadas as componentes psico-sociológicas do desenvolvimento econômico, McClelland and Sacial Stucture, Gocial Free Press, 1959, p. 196. 
estuda as condições culturais de uma sociedade no período imediatamente anterior àquele em que tem lugar um grande surto de atividade econômica, com o conseqüente crescimento da riqueza da comunidade. $O$ que se verificou é que o achievement level de uma sociedade não está relacionado obrigatoriamente com condições em que tenda a existir uma certa neutralidade afetiva, que se faz sentir particularmente nos métodos educacionais. Como exemplo, o autor em questão referese às práticas educacionais adotadas por famílias protestantes, calvinistas e metodistas entre outras, com relação ao desenvolvimento de um senso de independência da criança. As mães protestantes, pelo menos nos Estados Unidos, tendem a fazer com que seus filhos cuidem de si próprios o mais cedo possível, preparando-os para enfrentar por si só as dificuldades que lhes aparecerem. Um tal procedimento implica em preparar a criança para "deixar o lar" e "desligar-se dos pais" quando chegarem à idade adulta. A prática adotada por mães católicas, via de regra imigrantes - pois nos Estados Unidos o catolicismo foi uma religião trazida por alguns grupos de imigrantes - era a oposta, ou seja, a mãe tendia a prolongar em demasia suas atenções para com os filhos, retardando mesmo o processo de objetivação da criança, criando e mantendo vinculações afetivas que não a preparavam para a autonomia e para o "abandono dos pais". Estas duas atitudes educacionais, ou melhor, estas duas formas de relacionamento entre pais e filhos deveriam levar a um maior achievement level entre os protestantes e a outro sensivelmente menor entre os membros de famílias católicas.

Tal formulação seria a confirmação da tese weberiana, posteriormente desenvolvida por Winterbottom, segundo a qual ascetismo, austeridade e neutralidade afetiva conduziriam à criação de uma atitude que se manifestaria no impulso para o comportamento racional e para o acúmulo de riqueza. Em conclusão nos reportaríamos a McClelland que afirma ser " 0 desenvolvimento de autocontrole nos primeiros anos de vida um elemento promotor do elevado desempenho (high and achievement), uma vez que não seja o reflexo da coação, autoritarismo ou 'rejeição' por parte dos pais". 6

É conveniente observar que McClelland não se refere ao conteúdo doutrinário ou dogmático das duas religiões em questão, mas simplesmente a dois tipos de práticas encontradas. Nem acreditamos seja possível relacionar de maneira inequívoca a existência de dois tipos fundamentalmente diversos de relacionamento com a prática de uma determinada religião. Nada nos impede de aventar a hipótese de que nos encontramos diante de fatos acidentais sem conexão causal obrigatória. De qualquer forma nos utilizamos dos exemplos em questão porque acreditamos que fossem ilustrativos para o que estamos abordando.

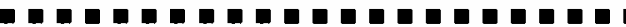 \\ A capacidade de organizar-se está diretamente relacionada \\ com a capacidade e a \\ possibilidade de \\ comunicação. A palavra escrita é de importância fundamental na vida de todas as formas de organização, particularmente das organizações formais.}

Estamos atentos ao fato de que ao insistirmos na relativa "neutralidade afetiva" como exigência organizacional estamos nos atendo ao modelo weberiano de eficiência, e não ignoramos as críticas que a formulação tem merecido ao longo das duas últimas décađas. Nossa afirmação manteve-se apenas atenta ao fato de que as tarefas organizacionais tendem hoje em dia sempre em direção às grandes organizações e nestas é impossível fugir ao tipo "burocrático" de administração. Não acreditamos que sejam válidas as análises sobre disfunções, uma vez que estas só podem ser válidas a partir de uma experiência burocrática suficientemente longa, $o$ que via de regra não ocorre em países onde as organizações ainda constituem elementos recém-chegados ao quadro institucional.

Numa sociedade como a brasileira, as organizações estão quase sempre permeadas de relações que têm sua origem em relações familiares ou de amizade. Ainda é grande a insegurança que se apossa das
6. McCLELLAND, David. The Achieving Society. Princeton, D. van Nostrana Company, Inc., 1961, p. 345. 
pessoas quando têm de estabelecer relacionamento formal, onde as relações de tipo simpático deixam de existir, e o primado deve pertencer à norma geral e abstrata. Um sentimento de desconforto e desconfiança permeia a realização de negócios com estranhos, ou a outorga de posições que envolvam poder de tomar decisões a pessoas que não pertençam ao círculo dos parentes, ou, quando muito, dos amigos. As chamadas "oligarquias" que ocupam posições-chave simultaneamente no comércio, na indústria, nos meios bancários e em última instância no próprio governo são via de regra, oligarquias de relacionamento familiar ou de amizade, sempre fundamentadas em relações de tipo simpático entre um chefe e seus subordinados e que deixam de lado a competência profissional formalmente comprovada ou o processo de avaliação de mérito. A ocupação de posições-chave na administração pública e de grupos de empresas privadas por homens que se relacionam a um determinado chefe, numa base puramente pessoal, é um evento corrente e aceito sem questionamento pela sociedade como um todo.

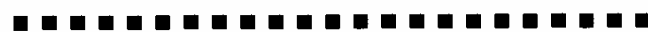

Numa formulação quase silogística, Etzioni afirma que a eficácia e a própria existência das organizações formais só são possíveis numa sociedade que tenha atingido as características de racionalidade e de objetivação sob forma da ação.

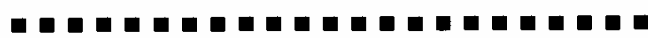

7. STINCHCOMBE, Arthur L. "Social Structure and Organizations". In: MARCH, James E. (org.) Handbook of Organizations. Chicago, Rand McNally and Co., 1965, pp. 150-3. cedidas acabaram por demonstrá-lo. A capacidade de objetivação sob forma de ação organizada elimina em grande parte $o$ "mito do herói", uma vez que as grandes realizações deixam de ser creditadas a um único indivíduo, para se tornarem acervo da comunidade. A partir de um certo nível de complexidade organizacional a ação organizada passa a ser uma necessidde e não é mais possível abandoná-la. Todavia, o progresso maior ou menor no caminho de organizações formais dependerá em grande parte do processo de socialização e do que esse venha gerar nos componentes da sociedade.

Numa universidade contemporânea não seria mais possível repetir o episódio do "doutor medieval" ou do "sábio helênico", pois que o próprio desenvolvimento da cultura não mais permite o enciclopedismo e o trabalho universitário será fatalmente o resultado de uma ação organizada. $O$ mesmo poderia ser dito de uma oficina artesanal e de uma indústria de certo porte. A oficina comportará o "artesão criador". A moderna indústria só criará através de suas equipes de especialistas e pesquisadores, agrupados no departamento de Pesquisa e Desenvolvimento.

\section{CONCLUSÕES}

Algumas observações de cunho sociológico permitiriam verificar que certas condições são essenciais para aumentar ou diminuir a capacidade de organizar-se de uma determinada comunidade. Assim é que as organizações formais, que constituíram o nosso objeto de especulação, porque são a melhor expressão alcançada da racionalidade, resultam de um processo evolutivo que tem suas raízes numa constelação social maior que são as organizações informais, dentre as quais avulta com especial importância os grupos primários. Vários fatores afetam a capacidade de organização, lato senso, de uma comunidade, e com mais intensidade ainda a capacidade de se criarem organizações formais. Dentre eles cumpre relacionar: o nível de alfabetização, a urbanização, a existência de uma economia monetária, a existência ou não de revoluções políticas e a própria densidade da vida social. ${ }^{7}$

Não acreditamos que seja necessário estendermo-nos muito sobre a alfabetiza- 
ção. A capacidade de organizar-se está diretamente relacionada com a capacidade $e$ a possibilidade de comunicação. A palavra escrita é de importância fundamental na vida de todas as formas de organização, particularmente das organizações formais. Todo grupo tem as suas tradições, e estas constituem parte integrante do grupo, e sem as tradições não há possibilidade de continuidade social. A organização formal possui uma tradição que se registra sob forma escrita e são os seus arquivos ou sua memória. Esta pressupõe a palavra escrita, e constitui o elemento fundamental para $o$ próprio processo decisório que é vital para a sobrevivência da organização formal.

A capacidade de uma determinada comunidade organizar-se dependerá da maior ou menor facilidade de que disponha para poder comunicar-se e a palavra escrita, quando as organizações têm de recobrir grandes espaços geográficos, é o único meio possível de comunicação. Além do mais, a alfabetização terá influência decisiva para aumentar a densidade da vida social de uma comunidade.

A urbanização é de particular importância para o aparecimento de organizações formais, na medida em que a própria cidade constitui uma organização formal, nitidamente diversa da comunidade rural. O nosso quadro de referências aplica-se à cidade ocidental, que se originou na Idade Média, enquanto oposição à "visão do mundo" e às relações de tipo místico e simpático vigentes na comunidade rural. As organizações formais tenderão a aparecer mais em sociedades em que há um predomínio do ethos urbano sobre o rural.

As revoluções políticas ou a sua ausência e a natureza dessas revoluções poderão desempenhar papel de importância no aparecimento de organizações formais. Um caso clássico é o aparecimento no México do PRI (Partido Revolucionário Institucional), como partido único que se implantou após a revolução. Ainda seria interessante citar o aparecimento de várias organizações formais na União Soviética após a revolução, e como conseqüência direta da mesma. Dentre elas sobressai em importância o próprio Partido Comunista da União Soviética, mas não é menos expressivo o aparecimento de todo um aparato burocrático, que vai desde os vários ministérios até as unidades produtoras que são as empresas, que indiscutivelmente não teriam sido possíveis sem a revolução.

Acreditamos não cair no truísmo se ao final apontássemos a própria densidade da vida social como outro fator a condicionar o aparecimento de organizações formais. A tautologia seria excusável na medida em que se reconheça que a melhor forma de aprender a organizar-se é organizando-se. A melhor medida do aprendizado é uma sucessão de experiências numerosas, não importando se bem ou malsucedidas. $\mathrm{Na}$ medida em que se admita que o processo de aprendizado, tanto no plano individual como no social, é uma seqüência de "erros e acertos", a nossa afirmação poderá ser sustentada.

No que diz respeito à formação de organizações formais que funcionem com eficácia em países não ocidentais, o que em nosso vocabulário significa subdesenvolvidos, os autores só apenas recentemente começaram a se ocupar da questão. A preocupação surge mais com Etzioni e os estruturalistas, na medida em que tratam de ver as organizações formais como parte da sociedade total. As afirmações de Amitai Etzioni no seu Modern Organizations são tão breves quanto desencorajadoras. ${ }^{8}$ Numa formulação quase silogística, afirma que a eficácia e a própria existência das organizações formais só são possíveis numa sociedade que tenha atingido as características de racionalidade $e$ de objetivação sob forma da ação. Ora tais atributos só são inteligíveis a partir do ethos ocidental, de onde se conclui que as sociedades não ocidentais não poderão organizar-se formalmente e se o fizerem cairão fatalmente na ineficácia, pois o ethos não ocidental condicionará inevitavelmente tais tipos de resultados.

Acreditamos que a "formulação da desesperança" mesmo que perfeitamente lógica e bem fundamentada não deve seduzir os que pretendem mudar e agir. Basicamente, encontraríamos duas maneiras para introduzir a racionalidade na ação organizada de sociedades não ocidentais. Em ambas as formas alguém ou alguns deverão fatalmente desempenhar o papel de demiurgos da razão. Uma via seria a da revolução política, com o pressuposto de que o grupo que viesse ocupar o poder se propusesse realizar a racionalidade social, mesmo se utilizando da violência se ne-
8. ETZIONI, Amitai, Modern Organizations. Englewood Cliffs, Prentice Hall, 1965, p. 114. 
cessário ao longo do processo. É o caminho radical, na medida em que um grupo adjudica-se o direito de investir contra o próprio ethos de um grupo. Uma segunda alternativa seria a crença na mudança gradativa sem a utilização sistemática da violência, e sem que uma revolução política forçosamente ocorresse. A partir daqui poderíamos tentar delinear quais os agentes de mudança (demiurgos) encontradiços numa sociedade pluralista, que é a existente na maioria dos países. Conquanto seja necessário reconhecer que numa determinada nação ou comunidade um grupo pode ter mais importância que os demais, ou melhor dizendo, que alguns grupos poderão ter mais influência que os demais, será sempre forçoso reconhecer vários grupos atuantes, com interesse possivelmente conflitantes, mas igualmente interessados em atuar socialmente.

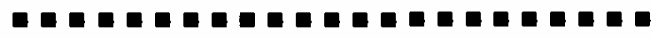 \\ Um elemento de grande importância no processo competitivo e que opera a favor da organização "estrangeira" ou multinacional é a sua maior capacidade administrativa, pois que é dotada de maior racionalidade, $o$ que resulta em maior eficácia.}

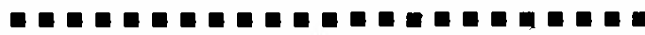

Antes de nos referirmos especificamente aos agentes de mudança, seria conveniente observar que antes de mais nada necessitamos grandemente de melhores estudos e reflexões sobre o problema das organizações formais em sociedades não ocidentais. Até o momento continuamos a repetir, quando se trata de interpretar nossas patologias organizacionais e nossa ineficácia coletiva, modelos explicativos weberianos, que no fundo se reduzem ao estudo weberiano das formas de dominação. O grande inconveniente é que tanto discípulos como mestres acabam por conceder vida e existência a modelos puros, passando a encontrá-los na própria sociedade em que estão inseridos. Nossas organizações formais fatalmente refletirão as peculiaridades de nossas culturas e $o$ afastamento de um padrão ocidental não significa obrigatoriamente algo a ser encara- do como definitivamente patológico e deviant. Nossas observações e comentários a respeito de nossas organizações limitamse a compará-las a um modelo europeu ou norte-americano e concluir pela ineficácia, perpetuando o histórico posicionamento província-metrópole.

Os principais agentes de mudança são organizações formais oriundas de sociedades ocidentais que se estabelecem num país não ocidental. Nesse sentido as empresas estrangeiras ou multinacionais constituem um agente de mudança na medida em que forçam as organizações nacionais não ocidentais à adoção de uma racionalidade maior a fim de poder enfrentar a competição. Freqüentemente se tem descrito o embate entre empresas "nacionais" e "estrangeiras" em termos de "imperialismo", onde $o$ arrivista tenta por todos os meios a extinção ou absorção da organização nacional existente. Sem nos determos sobre a questão, gostaríamos de lembrar que um elemento de grande importância no processo competitivo e que opera a favor da organização "estrangeira" ou multinacional é a sua maior capacidade administrativa, pois que é dotada de maior racionalidade, o que resulta em maior eficácia. Sob esse ponto de vista, sua ação pode ser vista como sendo estimulante para as organizações nacionais que se vêem obrigadas a incorporar aos seus padrões organizacionais uma racionalidade maior.

Outro agente de mudança pode ser constituído pelo processo educacional na medida em que ele se decidir pela modificação dos valores tradicionais de uma sociedade e que principie a introdução de valores próprios de uma sociedade voltada para a racionalidade e para a objetivação sob forma de ação organizada.

Finalmente, somos levados a reconhecer que o processo de introdução de maior eficácia nas organizações formais existentes numa sociedade não ocidental, e a criação de novas organizações formais que não partilhem dos mesmos vícios de comportamento vigentes nas mais antigas serão inevitavelmente um processo demorado e trabalhoso, na medida em que mudanças substanciais deverão ocorrer na própria cultura, pois é na sociedade maior que encontramos as raízes para uma ação organizada eficaz e racional. $\square$ 